\title{
An Investigation of Employee Performance Differences between Native and Immigrant Employees
}

\author{
Emad Anver ALBAYATI a Şule ERDEM TUZLUKAYA iD b \\ a Atılım University, Ankara, Turkey. Emadanwer84@gmail.com \\ b Atılım University, Ankara, Turkey. sule.tuzlukaya@atilim.edu.tr
}

\begin{tabular}{|c|c|}
\hline ARTICLE INFO & ABSTRACT \\
\hline $\begin{array}{l}\text { Keywords: } \\
\text { Employee performance } \\
\text { Immigration } \\
\text { Subjective assessment }\end{array}$ & 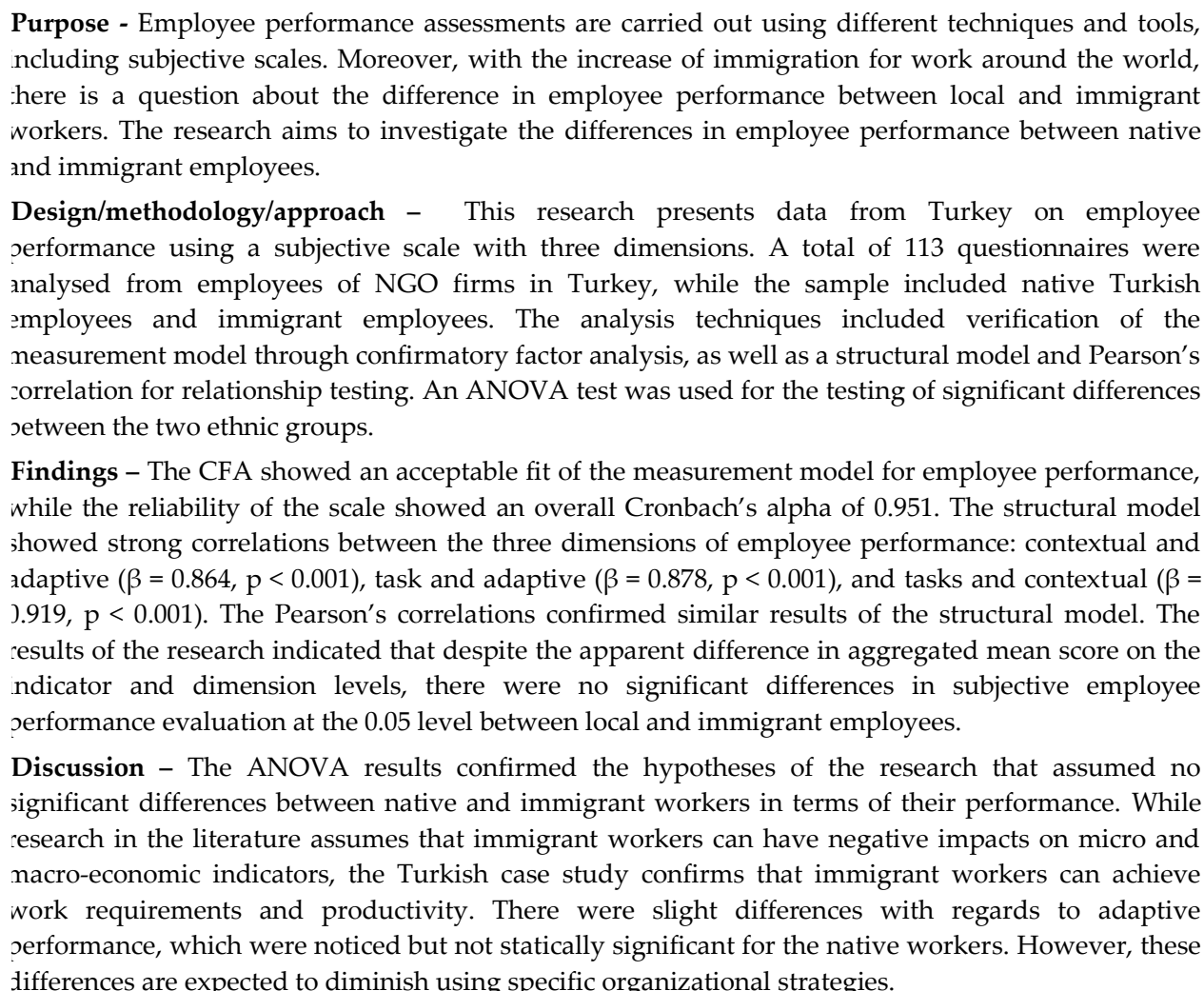 \\
\hline
\end{tabular}

\section{INTRODUCTION}

Employee performance also referred to as job performance, is defined as "the ability of a person to achieve targets and goals, in addition to levelling to the expectations of his supervision and management" (Shaikh, Tunio, \& Shah, 2017, p. 312). According to Aguinis (2009) the definition of employee performance is narrated through understanding behaviours, studying each behavioural pattern, and linking to the employee' appraisal. McCloy, Campel, \& Cudeck (1994) focused on the knowledge of the employee to determine his or her performance. The author discussed different types of knowledge, such as procedural and declarative. Tinofirei (2011, p. 15) defined employee performance as "the success in the completion of the task, as set and measured by a supervisor, based on acceptable standards that have been established, by utilizing the available resources effectively and efficiently". Griffin, Welsh, \& Moorhead (1981, p. 656) defined the term as "the contribution of the employee to the organization". All definitions agree that the supervisor should be able to measure tangible outcomes from the employee in order to determine performance. The literature, on the other hand, has focused on identifying the factors that influence employee performance as a recognized concept that can influence other performance criteria in the organization (Hatane, 2015). 
Pradhan \& Jena (2017) constructed an employee performance model based on three dimensions: Task performance, adaptive performance, and contextual performance. Task performance refers to the ability of the employee to work according to industry standards, multitask between several assignments, maintain passion for the role, perform highly in comparison with other team members, and the ability to perform tasks with minimal supervision. Contextual performance refers to the ability to take responsibility, offer advice to other team members, participate in discussions and meetings, coordinate tasks with team members, offer help to other team members, encourage team members, express empathy, and sympathy to colleagues, help new team members, and demonstrate effective communication skills (Griffin, Neal, \& Neale, 2000). Adaptive performance refers to the ability of the employee to respond to job changes, demonstrate flexibility in the role, carry out solutions through consensus, control emotions in stressful situations, adapt to changes in teamwork, adapt performance according to available information, and cope with organizational changes (Park \& Park, 2019).

Benghoul (2018) and Esen \& Binatli (2017) presented research results that assessed the effect of immigrant workers in Turkey on employment and economic factors. A negative relationship was found between increasing immigrant workers and each of inflation and growth rate (Benghoul, 2018), while there were no adverse effects on unemployment (Esen \& Binatli, 2017). Moreover, Carrasco, Jimeno, \& Ortega (2008) confirmed that immigrant workers did not negatively impact compensations of native workers or the employment rates in Spain. These studies suggest that immigrant employees have macro-economic effects; however, no research had addressed micro effects on the organization, especially in terms of performance. The aim of the current research is an evaluation of employee performance using a subjective scale for a comparison between Turkish and immigrant workers in Turkish organizations.

\section{LITERATURE REVIEW}

Employee performance is an integrated part of overall organizational performance, which collectively contributes to the organization's success and achieving higher productivity and competitive advantage. (Raza, Anjum, \& Zia, 2014). According to research, focusing on individual employee performance and appraisal is an effective strategy for driving organizational performance (Tatar, 2011). Shaheen, Naqvi, \& Khan (2013) tested the mediating effect of employee performance in improving organizational performance through putting efforts into employees' training. Employee's performance showed an impact of $26 \%$ on organizational performance based on a regression model with a 0.001 significance level. Therefore, it is evident that aspects enhancing employee's performance, including training, engagement, satisfaction, and morale, have a good potential to increase organizational performance (Diamantidis \& Chatzoglou, 2019).

Massoudi (2016) identified four main factors affecting employee performance, which are empowerment, transformational leadership, teamwork, and work environment. These factors were suggested as direct measurement dimensions for employee's performance, and also as key factors that impact it. The correlational analysis of the study showed positive moderate correlations between the four factors and employee's performance significant at the 0.05 level, while the highest correlation coefficient was for teamwork. Tuffaha (2020) reviewed the determinants of employee performance through a literature review of the most affecting factors of the concept.

The way knowledge is acquired, shared, and transferred within the organization is considered critical in providing the necessary information for the employee to act on them. The level of technological adoption in the organization is also important in providing the necessary tools for the employee. Environmental factors, including empowerment and culture, are shown as influential in determining employee performance. The support of the organization for innovation and creativity enables the employee to utilize knowledge and resources and take decisions that can make a difference in increasing competitive advantage (Tuffaha, 2020).

Ahmad \& Shahzad (2011) investigated the effect of three factors on employee performance: compensation, appraisal, and promotion. The research was applied to more than 100 university instructors. Employee's performance only showed a significant correlation at the 0.01 level with compensation practices, which had a positive weak nature. A positive moderate correlation was found between compensation and appraisal. The 
results of the study show that employee performance is more complex in determination and measurement than using a simplified scale for measurement. Therefore, any measurement technique needs to consider the several factors that represent the concept.

\section{RESEARCH DESIGN}

\subsection{Research Hypothesis}

While no correlation was found between immigrants and their job satisfaction, Chowan, Zeytinoglu, \& Cooke (2016) have presented a multiple regression model that showed a moderate negative effect of being an immigrant worker in Canada on job satisfaction $(\beta=-0.308, \mathrm{p}<0.01)$. Moreover, high performance work systems (HPWS) showed a positive impact on enhancing job satisfaction, including pay-for-performance $(\beta=$ $0.0890, \mathrm{p}<0.05)$. The results of the study suggest that being an immigrant can affect employee performance. Arasli, Arici, \& Ilgen (2019) examined human resources practices that can enhance engagement and retention for immigrant workers in North Cyprus, where Moderate positive correlations were found for adjustments, referred to as crafting, made in tasks (engagement $r=0.301$ and retention $r=0.305, p<0.01$ ), relations (engagement $r=0.212$ and retention $r=0.217, p<0.01$ ), and cognitive approach (engagement $r=0.221$ and retention $r=0.249, p<0.01$ ). Such results suggest that adjustments are required in operational and human resource systems to enhance immigrant employee performance. Furthermore, Horverak et al. (2013) studied the perception of managers towards immigrant workers during the hiring process. The study indicated that managers prioritize a person-job fit; however, it showed from the results that these decisions are biased against immigrants for cultural reasons while using performance as an excuse.

$\mathrm{H}$ : There is no statistically significant difference in employee performance between native and immigrant workers.

\subsection{Methods, Sample, and Data Collection}

The main aim of the study is to investigate the differences in performance between local and immigrant workers in Turkish organizations. The scale used for measurement consists of 23 items, which is adopted from Pradhan \& Jena (2017), using a subjective scale method that is based on self-evaluation of different aspects: Task, context, and adaptation. The items of the scale are distributed among the three main dimensions, as follows:

- Task performance: 6 items

- Contextual performance: 10 items

- Adaptive performance: 7 items

Data was collected through an electronic form from different NGOs in Turkey. Each of the items was evaluated on a 6-point Likert scale. Moreover, demographic data were collected from the participants, including gender, age, marital status, and education level. The questionnaire was distributed using an electronic form via email to a database of 700 employees in Turkey. A total of 148 questionnaires were filled. After checking for completion, 113 questionnaires were qualified for analysis. 64 questionnaires were submitted by local employees (56.64\%) and 49 questionnaires were submitted by immigrant employees $(43.36 \%)$. Data were checked for reliability and analysed through descriptive statistical techniques. Relationships between employee performance dimensions were investigated, as well as differences between local and immigrant employees in their evaluations.

\section{RESULTS}

\subsection{Reliability and Validity}

The reliability of the scale is checked using Cronbach's alpha, as shown in Table 1. The overall reliability of the employee performance scale is 0.951 , which is considered high. Cronbach's alpha for task performance, contextual performance, and adaptive performance are 0.805, 0.913, and 0.897, respectively. Based on the reliability analysis, the used scale and obtained data can be deemed acceptable. 
Table 1. Reliability analysis

Scale

Dimension

Task performance

Contextual performance

Adaptive performance
Cronbach's Alpha

0.805

0.913

0.951

0.897

\subsection{Construct Validity}

Confirmatory factor analysis is performed for the employee performance model used in the study, as illustrated in Figure 1, where the correlations between the three main dimensions of employee performance were found positive and strong. The validity of the model is confirmed through a few variables, as shown in Table 2. The IFI and CFI variables were found as 0.811 and 0.808 , respectively, which are deemed adequate. The RMSEA indicator was found as 0.115 , which is close to the 0.05 threshold targeted by the model considering the sample size. Therefore, the model is considered fit and allows further analysis of the variables (Cho et al., 2020).

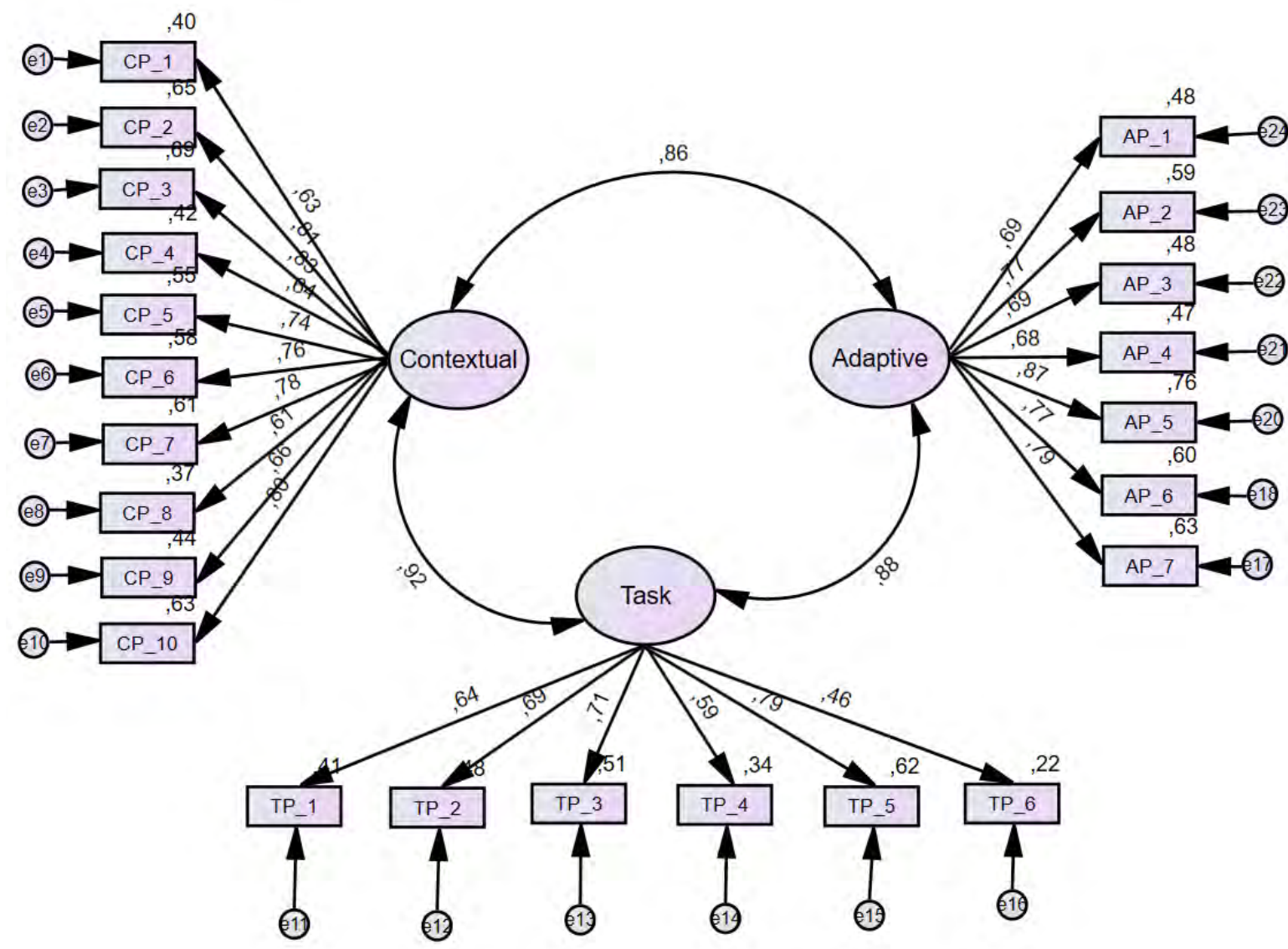

Figure 1. Confirmatory factor analysis for employee performance model

Table 2. Confirmatory factor analysis model fit variables

\begin{tabular}{ccccccc}
\hline Variable & CMIN & df & CMIN/DF & GFI & CFI & RMSEA \\
\hline Model & 565.420 & 227 & 2.491 & 0.811 & 0.808 & 0.115 \\
\hline
\end{tabular}




\subsection{Demographics and Descriptive Statistics}

Descriptive statistics of the participants' demographic data are presented in Table 3. In gender, $40.7 \%$ of the participants were males and 59.3\% were females. Most of the participants are in the age category between 30 and 39 years old $(51.3 \%)$, followed by the ones between 21 and 29 years old $(40.7 \%)$. Most of the participants are single $(66.4 \%)$ and the majority of the sample have a university degree $(62.8 \%)$.

Table 3. Descriptive statistics for demographics

\begin{tabular}{|c|c|c|c|c|c|}
\hline & Category & $\mathrm{N}$ & Percent & Mean & SD \\
\hline \multirow{2}{*}{ Gender } & Male & 46 & 40.7 & \multirow{2}{*}{1.59} & \multirow{2}{*}{0.493} \\
\hline & Female & 67 & 59.3 & & \\
\hline \multirow{3}{*}{ Age category } & 21 to 29 & 46 & 40.7 & \multirow{3}{*}{2.67} & \multirow{3}{*}{0.619} \\
\hline & 30 to 39 & 58 & 51.3 & & \\
\hline & 40 to 49 & 9 & 8.0 & & \\
\hline \multirow{2}{*}{ Marital status } & Single & 75 & 66.4 & \multirow{2}{*}{1.34} & \multirow{2}{*}{0.475} \\
\hline & Married & 38 & 33.6 & & \\
\hline \multirow{2}{*}{ Nationality } & Local & 64 & 56.6 & \multirow{2}{*}{1.43} & \multirow{2}{*}{0.498} \\
\hline & Immigrant & 49 & 43.4 & & \\
\hline \multirow{3}{*}{ Education } & High school & 10 & 8.8 & \multirow{3}{*}{4.19} & \multirow{3}{*}{0.580} \\
\hline & University & 71 & 62.8 & & \\
\hline & Higher & 32 & 28.3 & & \\
\hline
\end{tabular}

Table 4 shows the descriptive statistics of the employee performance scale. The mean values for all the items were above the $4^{\text {th }}$ point on the 6-point Likert scale, which is above the middle point. In task performance, local employees had higher means in three of the six items, while immigrant employees scored higher in the other three. In contextual performance, local employees aggregated a higher mean score in six of the ten items, while immigrant employees aggregated higher mean score in the other four. In adaptive performance, local employees aggregated higher mean scores in all seven items. Table 5 shows the mean scores of scale dimensions, where immigrant workers indicated a higher task performance mean and the local workers indicated higher contextual performance and adaptive performance means.

Table 4. Descriptive statistics for employee performance scale items

\begin{tabular}{lcccccc}
\hline & \multicolumn{9}{c}{ Descriptive } \\
\cline { 2 - 7 } Factor & \multicolumn{2}{c}{ All } & \multicolumn{2}{c}{ Local } & \multicolumn{2}{c}{ Immigrant } \\
\cline { 2 - 7 } & Mean & SD & Mean & SD & Mean & SD \\
\hline TP_1 & 5.12 & .980 & 5.02 & 1.046 & $\mathbf{5 . 2 4}$ & .879 \\
TP_2 & 5.35 & .832 & 5.39 & .902 & 5.29 & .736 \\
TP_3 & 5.13 & 1.065 & 5.27 & .996 & 4.96 & 1.136 \\
TP_4 & 4.99 & .901 & 4.86 & .974 & $\mathbf{5 . 1 6}$ & .773 \\
TP_5 & 5.35 & .834 & $\mathbf{5 . 4 2}$ & .887 & 5.27 & .758 \\
TP_6 & 5.00 & 1.188 & 4.81 & 1.424 & $\mathbf{5 . 2 4}$ & .723 \\
\hline CP_1 & 4.67 & 1.199 & 4.94 & 1.067 & 4.33 & 1.281 \\
CP_2 & 4.86 & .885 & 4.92 & .914 & 4.78 & .848 \\
CP_3 & 5.07 & .961 & $\mathbf{5 . 2 0}$ & 1.011 & 4.90 & .872 \\
CP_4 & 4.94 & 1.096 & $\mathbf{5 . 2 3}$ & .938 & 4.55 & 1.174 \\
CP_5 & 5.42 & .754 & 5.42 & .832 & $\mathbf{5 . 4 3}$ & .645 \\
CP_6 & 4.96 & .963 & 4.95 & 1.030 & $\mathbf{4 . 9 8}$ & .878
\end{tabular}


E.A. Albayat1 - Ş. Erdem Tuzlukaya 13/4 (2021) 3392-3401

\begin{tabular}{lcccccc}
\hline & \multicolumn{7}{c}{ Descriptive } \\
\cline { 2 - 7 } Factor & \multicolumn{2}{c}{ All } & \multicolumn{2}{c}{ Local } & \multicolumn{2}{c}{ Immigrant } \\
\cline { 2 - 7 } & Mean & SD & Mean & SD & Mean \\
\hline CP_7 & 5.20 & .918 & 5.13 & 1.047 & 5.31 & .713 \\
CP_8 & 5.24 & .889 & 5.23 & .886 & 5.24 & .902 \\
CP_9 & 5.40 & .797 & 5.41 & .830 & 5.39 & .759 \\
CP_10 & 5.24 & .889 & $\mathbf{5 . 3 8}$ & .845 & 5.06 & .922 \\
\hline AP_1 & 5.20 & .709 & $\mathbf{5 . 3 1}$ & .732 & 5.06 & .659 \\
AP_2 & 4.74 & 1.140 & $\mathbf{4 . 8 1}$ & 1.220 & 4.65 & 1.032 \\
AP_3 & 4.97 & .995 & $\mathbf{5 . 0 6}$ & 1.022 & 4.86 & .957 \\
AP_4 & 5.10 & .916 & 5.30 & .849 & 4.84 & .943 \\
AP_5 & 5.19 & .851 & $\mathbf{5 . 3 1}$ & .889 & 5.02 & .777 \\
AP_6 & 5.15 & .826 & $\mathbf{5 . 2 3}$ & .831 & 5.04 & .815 \\
AP_7 & 5.02 & .906 & $\mathbf{5 . 0 3}$ & .890 & 5.00 & .935 \\
\hline
\end{tabular}

Table 5. Descriptive statistics for employee performance overall evaluation and scale dimensions

\begin{tabular}{ccccccc}
\hline \multirow{2}{*}{ Dimension } & \multicolumn{7}{c}{ Descriptive } \\
\cline { 2 - 7 } & Mean & SD & Mean & SD & Mean & SD \\
\cline { 2 - 7 } TP & 5.16 & .694 & 5.13 & .780 & 5.19 & .568 \\
CP & 5.10 & .706 & 5.18 & .772 & 5.00 & .600 \\
AP & 5.05 & .719 & 5.15 & .753 & 4.92 & .657 \\
\hline
\end{tabular}

\subsection{Correlational Matrix}

A correlational analysis was performed between the overall evaluation and dimensions of the employee performance scale, as shown in Table 6 . The analysis showed strong positive correlations between employee performance (EP) and its dimensions. In correlations with employee performance, contextual performance had the highest correlation $(\varrho=0.936, \mathrm{p}<0.01)$, followed by adaptive performance $(\mathrm{Q}=0.919, \mathrm{p}<0.01)$, and task performance $(\varrho=0.909, \mathrm{p}<0.01)$. Among the variables of employee performance, contextual performance and adaptive performance had the strongest correlation $(\varrho=0.802, p<0.01)$. Task performance had the strongest correlation with contextual performance $(\varrho=0.783, p<0.01)$, followed with its correlation with adaptive performance $(\varrho=0.733, \mathrm{p}<0.01)$.

Table 6. Correlational analysis for employee performance (EP) scale $(\mathrm{p}<.05)$

\begin{tabular}{ccccc}
\hline \multicolumn{1}{c}{ EP } & TP & CP & AP \\
\hline EP & 1 & & & \\
TP & $.909^{* * *}$ & 1 & & \\
CP & $.936^{* * *}$ & $.783^{* *}$ & 1 & 1 \\
AP & $.919^{* * *}$ & $.733^{* *}$ & $.802^{* *}$ & 1 \\
\hline
\end{tabular}

**. Corelation is significant at the 0.01 level (2-tailed).

\subsection{Regression Analysis through Structural Modelling}

The standardized factors of the model indicators were all found significantly influential as confirmed by the regression weights presented in Table 7. All factors were highly influential on their dimensions. In 


\section{E.A. Albayat1 - Ş. Erdem Tuzlukaya 13/4 (2021) 3392-3401}

contextual performance, CP3 had the highest effect $(\beta=0.831)$. In task performance, TP5 had the highest effect $(\beta=0.789)$. In adaptive performance, AP5 has the highest influence $(\beta=0.871)$. All effects are significant at $\mathrm{p}<0.001$.

Table 7. Standardized regression weights for confirmatory factor analysis paths

\begin{tabular}{|c|c|c|c|c|c|c|}
\hline \multicolumn{3}{|c|}{ Analysis Path } & $\beta$ & SE & $\mathrm{CR}$ & $\mathbf{P}$ \\
\hline CP_1 & $\leftarrow$ & Contextual & .631 & .113 & 41.443 & .000 \\
\hline CP_2 & $\leftarrow$ & Contextual & .809 & .083 & 58.352 & .000 \\
\hline CP_3 & $\leftarrow$ & Contextual & .831 & .090 & 56.091 & .000 \\
\hline CP_4 & $\leftarrow$ & Contextual & .645 & .103 & 47.889 & .000 \\
\hline CP_5 & $\leftarrow$ & Contextual & .743 & .071 & 76.518 & .000 \\
\hline CP_6 & $\leftarrow$ & Contextual & .762 & .091 & 54.804 & .000 \\
\hline CP_7 & $\leftarrow$ & Contextual & .780 & .086 & 60.277 & .000 \\
\hline CP_8 & $\leftarrow$ & Contextual & .611 & .084 & 62.633 & .000 \\
\hline CP_9 & $\leftarrow$ & Contextual & .660 & .075 & 72.032 & .000 \\
\hline CP_10 & $\leftarrow$ & Contextual & .796 & .084 & 62.633 & .000 \\
\hline TP_3 & $\leftarrow$ & Task & .713 & .100 & 51.237 & .000 \\
\hline TP_4 & $\leftarrow$ & Task & .586 & .085 & 58.864 & .000 \\
\hline TP_2 & $\leftarrow$ & Task & .690 & .078 & 68.288 & .000 \\
\hline TP_1 & $\leftarrow$ & Task & .642 & .092 & 55.499 & .000 \\
\hline TP_5 & $\leftarrow$ & Task & .789 & .078 & 68.269 & .000 \\
\hline TP_6 & $\leftarrow$ & Task & .464 & .112 & 44.750 & .000 \\
\hline AP_4 & $\leftarrow$ & Adaptive & .682 & .086 & 59.169 & .000 \\
\hline AP_3 & $\leftarrow$ & Adaptive & .695 & .094 & 53.125 & .000 \\
\hline AP_5 & $\leftarrow$ & Adaptive & .871 & .080 & 64.783 & .000 \\
\hline AP_2 & $\leftarrow$ & Adaptive & .767 & .107 & 44.230 & .000 \\
\hline AP_6 & $\leftarrow$ & Adaptive & .774 & .078 & 66.271 & .000 \\
\hline AP_1 & $\leftarrow$ & Adaptive & .690 & .067 & 78.005 & .000 \\
\hline AP_7 & $\leftarrow$ & Adaptive & .795 & .085 & 58.863 & .000 \\
\hline
\end{tabular}

The results of the correlational analysis were also confirmed through the structural model obtained for the confirmatory factor analysis, as shown in Table 8, through positive strong effects. The model showed the highest influence of task performance on contextual performance $(\beta=0.919, \mathrm{p}<0.001)$, followed by the influence of task performance on adaptive performance $(\beta=0.878, p<0.001)$, and the influence of contextual performance on adaptive performance $(\beta=0.864, \mathrm{p}<0.001)$.

Table 8. Correlation paths between employee performance dimensions

\begin{tabular}{|c|c|c|c|c|c|c|}
\hline \multicolumn{3}{|c|}{ Analysis Path } & \multirow{2}{*}{$\begin{array}{c}\beta \\
.864\end{array}$} & \multirow{2}{*}{$\begin{array}{l}\text { SE } \\
.068\end{array}$} & \multirow{2}{*}{$\frac{\text { CR }}{4.640}$} & \multirow{2}{*}{$\begin{array}{c}\mathbf{P} \\
.000\end{array}$} \\
\hline Adaptive & $\leftarrow$ & Contextual & & & & \\
\hline Adaptive & $\leftarrow$ & Task & .878 & .058 & 4.657 & .000 \\
\hline Contextual & $\leftarrow$ & Task & .919 & .095 & 4.542 & .000 \\
\hline
\end{tabular}

\subsection{Variance Analysis between Locals and Immigrants}

A one-way ANOVA test was performed to investigate the differences in employee performance evaluations between participants based on their nationality, as shown in Table 9. The findings of the analysis show that there are no significant differences between local and immigrant employment at 0.05 significance level in the variable and its sub-dimensions. 
E.A. Albayat1 - Ş. Erdem Tuzlukaya 13/4 (2021) 3392-3401

Table 9. One-way ANOVA test for differences in employee performance evaluations between local and immigrant employment

\begin{tabular}{ccccccc}
\hline & & Sum of Squares & df & Mean Square & F & Sig. \\
\hline \multirow{3}{*}{ TP } & BG & .122 & 1 & .122 & .252 & .617 \\
& WG & 53.783 & 111 & .485 & & \\
\hline \multirow{3}{*}{ CP } & Total & 53.905 & 112 & & & \\
& BG & .953 & 1 & .953 & 1.930 & .168 \\
& WG & 54.817 & 111 & .494 & & \\
\hline \multirow{2}{*}{ AP } & Total & 55.770 & 112 & & & .095 \\
& BG & 1.437 & 1 & 1.437 & 2.829 & \\
\hline \multirow{2}{*}{ EP } & WG & 56.407 & 111 & .508 & & .352 \\
& Total & 57.845 & 112 & & .371 & \\
& BG & .371 & 1 & .423 & & \\
\hline
\end{tabular}

\section{CONCLUSION AND DISCUSSION}

The purpose of the study was to look into the differences in employee performance between local and immigrant workers in Turkish organizations. The confirmatory factor analysis performed on the used employee performance scale revealed an acceptable model fit with good intercorrelations between the indicators within the structural model. Pearson's rho explanatory analysis confirmed strong positive correlations between the variable's dimensions. The one-way ANOVA test for differences between native and immigrant employees revealed no significant differences in overall employee performance or any of its sub-dimensions: task, contextual, or adaptive. Thus, the hypothesis of the research stating " $\mathrm{H}$ : There is no statistically significant difference in employee performance between native and immigrant workers" is accepted/ supported.

Despite research that showed that immigrant worker has impacts on economic and organizational indicators, the current research indicates that there is no difference in employee performance evaluations between local and immigrant employees.. The descriptive statistics showed higher mean scores balanced between local and immigrant workers for task performance and contextual performance. However, local Turkish employees showed higher mean scores for adaptive performance, which could be attributed to them being used to the culture and work environment. Employee empowerment can be used in this aspect as an effective tool to enhance the adaptation of immigrant employees into the organization, as Konakay et al. (2021) showed its positive effects on employee performance. Tetik (2019) confirmed a positive relationship of organizational socialization strategies (education, organizational understanding, support, and expectation management), which is suggested as another tool to diminish any possible differences, on work motivation and performance. The utilized scale for the subjective measurement of employee performance showed high reliability in measuring the concept through Cronbach's alpha and the correlational analysis between its dimensions. Therefore, it is recommended to use the scale for future evaluations.

The research is limited to the case study of NGOs operating in Turkey, which requires verification in other organizational and national contexts. Furthermore, future research can focus on other types of organizations in Turkey to confirm or argue against the obtained results. The sample used in this study has its special characteristics due to the high level of education of the sample and high proficiency in Turkish language. Results in future research can differ if the scale is applied to craftsmen, handy workers, skilled labour, and unskilled labour. 


\section{REFERENCES}

Aguinis, H. (2009). Performance Management (2nd ed.). Prentice Hall.

Ahmad, S., \& Shahzad, K. (2011). HRM and employee performance: A case of university teachers of Azad Jammu and Kashmir (AJK) in Pakistan. African Journal of Business Management, 5(13), 5249-5253.

Arasli, H., Arici, H. E., \& Ilgen, H. (2019). Blackbox between job crafting and job embeddedness of immigrant hotel employees: a serial mediation model. Economic Research, 32(1), 3935-3962.

Benghoul, M. (2018). The Impact of Refugees on the Turkish Workforce. 4th International Social Science Congress (pp. 301-309). Nevşehir: Nevşehir Hacı Bektaş Veli University.

Carrasco, R., Jimeno, J. F., \& Ortega, A. C. (2008). The effect of immigration on the labor market performance of native-born workers: some evidence for Spain. Journal of Population Economics, 21, 627-648.

Cho, G., Hwang, H., Sarstedt, M., \& Ringle, C. M. (2020). Cutoff criteria for overall model fit indexes in generalized structured component analysis. Journal of Marketing Analytics, 8, 189-202.

Chowan, J., Zeytinoglu, I. U., \& Cooke, G. B. (2016). Immigrants and job satisfaction: Do high performance work systems play a role? Economic and Industrial Democracy, 37(4), 690-715.

Diamantidis, A. D., \& Chatzoglou, P. (2019). Factors affecting employee performance: an empirical approach. International Journal of Productivity and Performance Management, 68(1), 171-193.

Esen, O., \& Binatli, A. O. (2017). The Impact of Syrian Refugees on the TurkishEconomy: Regional Labour Market Effects. Social Sciences, 6.

Griffin, M. A., Neal, A., \& Neale, M. (2000). The contribution of task performance and contextual performance to effectiveness: Investigating the role of situational constraints. Applied Psychology: An International Review, 49(3), 517-533.

Griffin, R. W., Welsh, A., \& Moorhead, G. (1981). Perceived Task Characteristics and Employee Performance: A Literature Review. The Academy of Management Review, 6(4), 655-664.

Hatane, S. E. (2015). Employee satisfaction and performance as intervening variables of learning organization on financial performance. Procedia - Social and Behavioral Sciences, 211, 619-628.

Horverak, J. G., Bye, H. H., Sandal, G. M., \& Pallesen, S. (2013). Managers' Evaluations of Immigrant Job Applicants: The Influence of Acculturation Strategy on Perceived Person-Organization Fit (P-O Fit) and Hiring Outcome. Journal of Cross-Cultural Psychology, 44(1), 46-60.

Konakay, G., Akdemir, A., \& Mercanlioglu, A. C. (2021). The Effect of Organizational Innovation and Employee Empowerment on Job Performance: A Case of an Industrial Firm. Journal of Business Research - Turk, 13(1), 980-993.

Massoudi, A. H. (2016). Employees performance dimensions in Kurdistan region hotel industry. International Journal of Recent Scientific Research, 7(10), 13534-13539.

McCloy, R. A., Campel, J. P., \& Cudeck, R. (1994). A confirmatory test of a model performance determininents. Journal of Applied Psychology, 79(4), 493-505.

Park, S., \& Park, S. (2019). Employee Adaptive Performance and Its Antecedents: Review and Synthesis. Human Resource Development Review, 18(3), 294-324. 
E.A. Albayat1 - Ş. Erdem Tuzlukaya 13/4 (2021) 3392-3401

Pradhan, R. K., \& Jena, L. K. (2017). Employee Performance at Workplace: Conceptual Model and Empirical Validation. Business Perspectives and Research, 5(1), 1-17.

Raza, H., Anjum, M., \& Zia, S. M. (2014). The Impacts of Employee's Job Performance Behavior and Organizational Culture on Organizational Productivity in Pharmaceutical Industries in Karachi. Intercisciplinary Journal of Contemporary Research in Business, 5(12), 385-400.

Shaheen, A., Naqvi, S. M., \& Khan, M. A. (2013). Employees Training and Organizational Performance: Mediation by Employees Performance. Interdisciplinary Journal of Contemporary Research in Business, $5(4), 490-503$.

Shaikh, M. R., Tunio, R. A., \& Shah, I. A. (2017). Factors Affecting to Employee's Performance: A Study of Islamic Banks. International Journal of Academic Research in Accounting, Finance and Management Sciences, 7(1), 312-321.

Tatar, E. L. (2011). The importance of measuring individual performance to increase organizational performance. Journal of Defense Resources Management, 1(2), 113-118.

Tetik, S. (2019). The Effect on Work Motivation of Organizational Socialization in Public Organizations: A Research in Ihsaniye District. Journal of Business Research - Turk, 11(3), 1779-1791.

Tinofirei, C. (2011). The Unique Factors Affecting Employee Performance In Non Profit Organisations. University of South Africa.

Tuffaha, M. (2020). The determinants of employee's performance: A literaure review. Journal of Economics and Management Sciences, 3(3), 14-24. 